Paper No: SCARA-1.05-18, (84)

\title{
The Lethal Range Testing of Effective 80mm Air to Ground Warhead
}

\author{
Ali M. Zain*, Mohammed A. Abdalla*, Mohamed F.M. Ahmed*, Salaheldin A.M. Badreldin*, Mohamed \\ Muntaga* \\ *Sabigat Industrial Complex, Khartoum, Sudann \\ Email: ali005039@gmail.com
}

\begin{abstract}
The air force is the most important weapon during wars and battles. Through it, armies can control and isolate enemy territory, carry out their own operations and missions, allows for increased bombing, tactical air support for ground forces, parachuting, airdrops, and the passage of cargo planes. Countries are working to enhance their air force by increasing the number of their aircraft and providing them with the latest modern technologies in monitoring targets, accurate and efficient missiles. This paper will present a completely new design of $80 \mathrm{~mm}$ controlled fragmentation warhead for air to surface missile has been designed and tested, the results of experiment showed a good performance for tactical characteristics such as lethal range which is about 19 meters.
\end{abstract}

Key words-Composition B, Lethal range, Arena test.

\section{INTRODUCTION}

Warhead is specific device which caused damage by the action of an explosive that accelerate metal or produced blast effects to damages a desired target and renders it incapable of performing its function by produce sufficient lethal effect at the right time to destroy or incapacitate the target [1], [2]. Early designs utilized an iron ball with gun powder filling which was ignited by using a piece of slow burning match inserted in side [2]. Warheads include all types of projectiles such as high explosive, incendiary, illuminating, nuclear, and biological [2], [3]. The high explosive warheads can be divide into two categories, directed energy and omnidirectional [3]. Directed energy warhead focus the explosive energy by the use of cavity lined with metal, and can be divided further into shaped charge, hemispherical charge, and explosively formed penetrators [4]. Omnidirectional warheads can be divided into fragmentation and blast warheads [1].

A fragmenting warhead may be define as warheads that produce either many small fragments of low penetration efficiency or a reduced number of fragments that have a greater penetration effect [5]. The armor protection, target type and the required lethal zone of the warhead determine the optimum size of the fragments for a given size of warhead [6]. The main groups of fragments types are natural fragmentation, controlled fragmentation, and preformed fragments. In natural fragmentation warhead the explosive charge is detonated in a casing made of homogenous material, the fragments will be generated naturally after metallic case collapsed under high explosive charge detonating, while the preformed fragments prepared before warhead filling with explosive charge such as balls, cubes and so on [4], [6], [7]. The controlled fragments can be made by making grooves on the outside or inside, or zone embrittlement in the casing, or grooves in the high explosive charge to make weak points or lines that can control fragments shapes and weight [6]. High explosive warheads lethal radius is an important terminal-ballistics parameter. When the projectile has a larger lethal radius, we can decrease the number of warheads for target neutralization, that means increasing warheads lethal radius lead to decrease the number of warheads for target neutralization, which can be significant from tactical, economic and logistic point of view when conducting military operations [8], [9]. There are many factors influencing warhead efficiency and lethal radius (warhead geometry, mechanical characteristics of warhead components, detonator type, explosive detonation parameters, detonation height, impact angle and fuze type, etc). Due to complexity of these parameters, till now there is no comprehensive model for estimation the terminal-ballistics parameters [8].

In this work the warhead lethal radius was calculated based on American Vulnerability Model for Military Personnel. This model defines lethal radius as distance from the explosion at which there is an efficient fragment with a kinetic energy not less than $80 \mathrm{~J}$ (which is enough to kill or obstruct person) and density of $1 \mathrm{frag} / \mathrm{m}^{2}$, which assumed that the human target exposed area to the warhead is $1 \mathrm{~m}^{2}$ [8], [9].

Arena Test is a test used to determine spatial fragments distributions, fragments concentration density per stradian and fragments mass distribution in space. At the arena fragmentation test, fragments concentration density per steradian is measured when projectile or warhead putted in vertical or horizontal position at a certain distance from the ground. After the warhead detonation, number of perforations at wooden or metal sectors counted and the density of perforations number per meter square are calculated for each sector to obtain the lethal radius [1], [8], [9].

\section{MOdel Description AND EXPERIMENTAL WORK}

Our warhead model consists of steel case with inside notching to control fragments shape and size, explosive charge, 


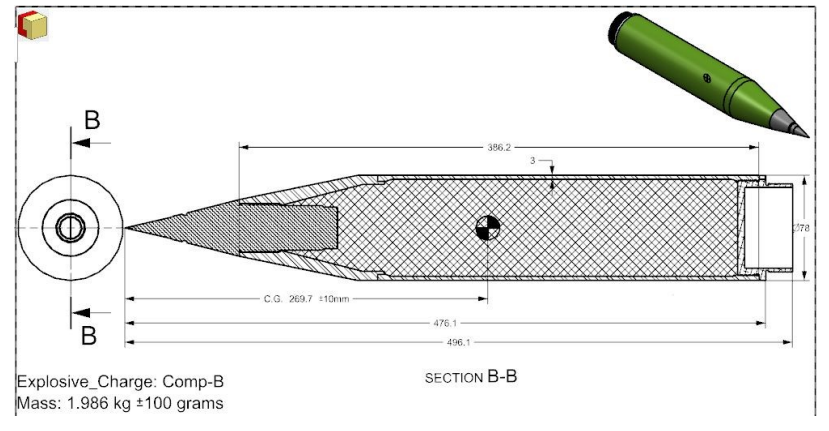

Fig. 1. $122 \mathrm{~mm}$ with composite material warhead.

dummy fuze and rear cover as shown in Fig. 1, and the main parameters of model shown in TABLE I.

TABLE I

WARHEAD INFORMATION

\begin{tabular}{ll}
\hline Model Name & $80 \mathrm{~mm}$ \\
\hline Model Type & Fragmentation/Blast \\
Fragmentation type & Controlled fragments \\
Model Weight $(\mathrm{kg})$ & 4.83 \\
Case Material & Steel \\
Case Density $(\mathrm{kg} / \mathrm{m} 3)$ & 7860 \\
Case Weight $(\mathrm{kg})$ & 2.81 \\
Explosive Material & Comp-B \\
Explosive Density $(\mathrm{kg} / \mathrm{m} 3)$ & 1610 \\
Explosive Weight $(\mathrm{kg})$ & 2.02 \\
Booster Material & RDX \\
\hline
\end{tabular}

Evaluating the fragmentation efficiency and lethal radius are based on experimental method in wooden arena which consists of four circular sectors with distance $10,15,20$ and $25 \mathrm{~m}$, each sector contains of 10 panels its dimensions are: $1 \mathrm{~m}$ for width and $1.6 \mathrm{~m}$ for height as shown in Fig. 2.

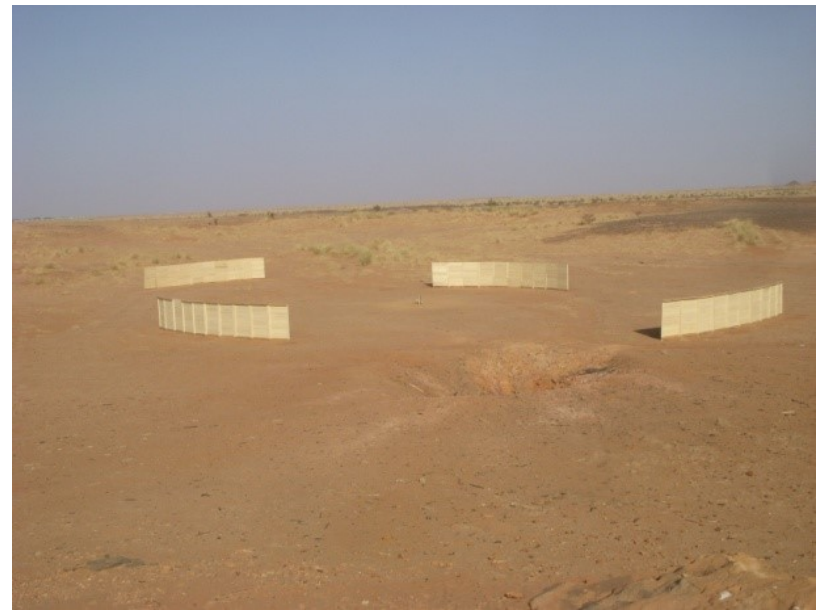

Fig. 2. Arena test facility.

The model does not take into account the condition and protection of the human target and the fragment impact location into the human body. The $80 \mathrm{~mm}$ model settled vertically in wooden arena center with $10 \mathrm{~cm}$ distance from the ground, this saved with wooden bench Fig. 3, the model initiated electrically from safety distance with electrical capsules.

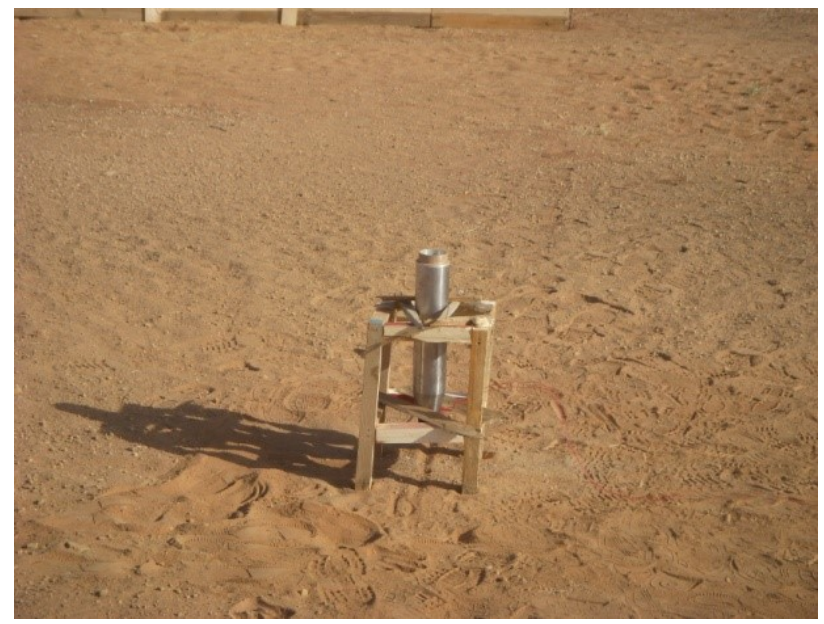

Fig. 3. Warhead position before test.

\section{EXPERIMENTAL RESULTS}

Form the experimental work described before, three warhead models exploded and the penetrated fragments in all sectors was counted Fig. 4 and full results was tabulated in TABLE II.

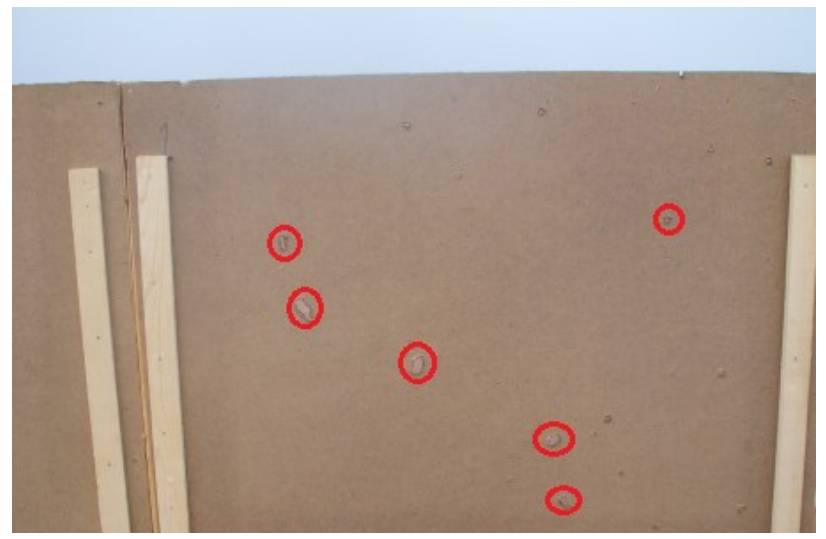

Fig. 4. Fragments penetration arena panels.

TABLE II

WARHEAD INFORMATION

\begin{tabular}{lllll}
\hline $\begin{array}{c}\text { Panel } \\
\text { No }\end{array}$ & $\begin{array}{c}10 \mathrm{~m} \\
\text { Fragments }\end{array}$ & $\begin{array}{c}15 \mathrm{~m} \\
\text { Fragments }\end{array}$ & $\begin{array}{c}20 \mathrm{~m} \\
\text { Fragments }\end{array}$ & $\begin{array}{c}25 \mathrm{~m} \\
\text { Fragments }\end{array}$ \\
\hline 1 & 48 & 12 & 3 & 3 \\
2 & 36 & 9 & 9 & 1 \\
3 & 43 & 9 & 12 & 1 \\
4 & 42 & 12 & 4 & 1 \\
5 & 36 & 9 & 4 & 1 \\
6 & 36 & 9 & 9 & 2 \\
7 & 50 & 13 & 6 & 1 \\
8 & 48 & 10 & 6 & 1 \\
9 & 41 & 12 & 6 & 4 \\
10 & 46 & 12 & 1 & 1 \\
\hline
\end{tabular}


From this data we can note the following points

1) The test shows homogenous fragments distribution (no effective outliers).

2) The range of penetrated fragment in each sector is 3650, 9-13, 1-12 and 1-4 fragment/panel.

3) This data can be plotted in Fig. 4, which show the fragmentation density versus distance from explosion center.

4) From obtained data, dependency of fragments concentration density per meter square as a function of sector distance, at which fragments concentration density of 1 perforation per meter square was obtained, this distance is warhead lethal radius (American standard) [8], [9], which means that warhead with greater efficiency radius has corresponding greater lethal zone.

5) For this warhead model $80 \mathrm{~mm}$ the lethal efficiency radius is $19.5 \mathrm{~m}$.

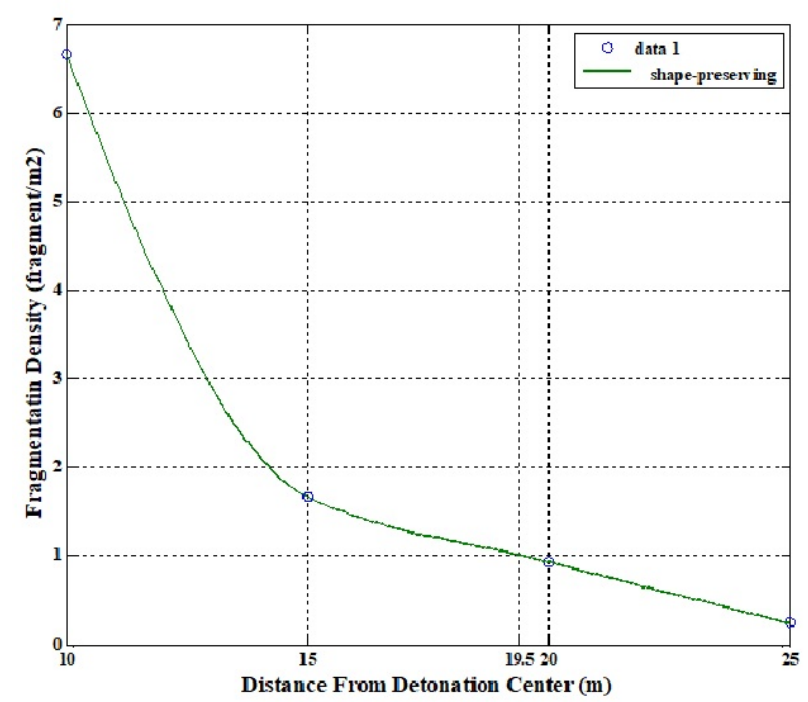

Fig. 5. distances from the arena center Vs fragmentation density per $\mathrm{m}^{2}$

\section{CONCLUSiOns}

In conclusion, the lethal radius of the $80 \mathrm{~mm}$ warhead model was around 19 meters. The three warhead models were tested under the same conditions. The weights for three models are: $4.71,4.82$ and $4.83 \mathrm{~kg}$.

\section{ACKNOWLEDGMENT}

The authors of this article acknowledge the financial support of Military Defense System Sudan MASAD.

\section{REFERENCES}

[1] M. Abdalla, Measurements and calculations of optimum terminal ballistic parameters for rocket warheads. Karary University.

[2] S. Jaramaz, Warheads Design and Terminal Ballistics. Belgrade: University of Belgrade.

[3] J. Mathieu and H. Stucki Military high explosives:Chimia, vol. 2004, no. 58.

[4] J. Carleone, "Tactical missile warheads. progress in astronautics and aeronautics."

[5] "Armaments and energetic materials technology."
[6] M. Held, "Fragmentation warheads," in Tactical Missile Warheads (J. Carleone, ed.), American Institute of Aeronautics and Astronautics, 1st ed.

[7] R. Lloyd, "Conventional warhead systems physics and engineering design."

[8] B. Zecevic, J. Terzic, and A. Catovic, "Influence of warhead design on natural fragmentation performances," in 15th DAAAM Interrnational Symposium, 2004, p. 34.

[9] A. Catovic and E. Kljuno, "A novel method for determination of lethal radius for high-explosive artillery projectiles:def," Technol.:2021:17, vol. 4. 